\title{
Study the influence of a new ball burnishing technique on the surface roughness of AISI 1018 low carbon steel
}

\author{
A.A. Ibrahim, Tamer Khalil, Tarik Tawfeek* \\ Mechanical Engineering Department, Faculty of Engineering, Benha University, 108-Shoubra Street-Cairo- Egypt \\ *Corresponding author E-mail: tariktewfic@yahoo.co.uk
}

Copyright $\left({ }^{\circ} 2015\right.$ A.A. Ibrahim et al. This is an open access article distributed under the Creative Commons Attribution License, which permits unrestricted use, distribution, and reproduction in any medium, provided the original work is properly cited.

\begin{abstract}
Hard roller burnishing with a ball tool is a surface-finishing where a free-rotating tool rolls over the machined surface under high pressures and flattens the surface roughness peaks by cold work. In the present work, a new burnishing technique has been applied which enables both single and double ball burnishing process in site after turning without releasing the specimen. Sets of experiments are conducted to investigate the influence of burnishing force, feed, speed and number of tool passes on surface roughness of AISI 1018 Low Carbon Steel specimens. Burnishing results showed significant effectiveness of the new burnishing technique in the process. The results revealed that minimum surface roughness are obtained by applying the double ball burnishing process on AISI 1018 Low Carbon Steel specimens. Improvement in surface finish can be achieved in both single and double ball burnishing by increasing the number of burnishing tool passes. The results are presented in this paper.
\end{abstract}

Keywords: Ball Burnishing; Burnishing Force; Burnishing Speed; Number of Burnishing Tool Passes; Surface Roughness.

\section{Introduction}

Finishing processes are commonly used to improve the surface finish of the machined components. These processes can be classified as chip removal process such as grinding and chip less process such as burnishing [1-3]. Burnishing is considered as a cold- working finishing process, differs from other cold-working, surface treatment processes such as shot peening, and sand blasting etc., in that it produces a good surface finish. Also, burnishing is economically beneficial, because it is a simple and less costly process, requiring less time. Semi-skilled operators are enough to obtain a high- quality surface finish [4-6].

Several works have been carried out recently to improve surface characteristics by using ball and roller burnishing process. The process, as shown in figure 1, is one of the surface finishing processes that results in a plastic deformation on the specimen surface by using a ball [7-9]. Plastic flow of the original asperities occurs when the yield point of the specimen's material is exceeded [10]; consequently the asperities will be flattened.

Burnishing process has many advantages over the other finishing processes, the improvement of the surface roughness through the burnishing process generally ranged between $40 \%$ and $90 \%$ [11-13]. Compressive stresses are also induced in the surface layer, giving several improvements to mechanical properties. Burnishing can improve both the surface strength and roughness [14]. 


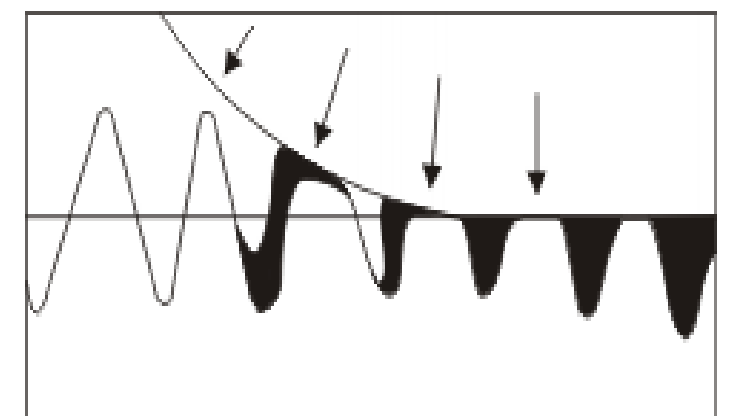

Fig. 1: Material Flow From Peaks to Valleys in the Burnishing Process [5].

In this work a new burnishing technique has been presented which enables both single and double ball burnishing process in site after turning on a conventional lathe without releasing the specimen. The main aim of this work has been dedicated to study the influence of the new burnishing technique on the surface roughness of AISI 1018 Low Carbon Steel.

The variable burnishing parameters selected for the experimental work were the burnishing force, feed, speed and the number of burnishing tool passes. These selected burnishing parameters are the most effective parameters in the ball burnishing process [15] and [16]. The influence of the selected burnishing parameter upon the final surface roughness of AISI 1018 Low Carbon Steel specimens has been demonstrated.

\section{Material tool and experimental procedure}

\subsection{Test specimens}

In this study AISI 1018 Low Carbon Steel has been selected due to its importance in industry. The chemical composition and mechanical properties of the test specimens is $0.18 \% \mathrm{C}, 0.21 \% \mathrm{~S}$, and $0.60 \% \mathrm{Mn}$, and mechanical properties are $\sigma_{\mathrm{u}}=475 \mathrm{~N} / \mathrm{mm}^{2}$, and $\mathrm{BHN}=143$.

The specimens were received as a cylindrical bar of $32 \mathrm{~mm}$ diameter. The bars were cut to the appropriate length $(85$ $\mathrm{mm}$ ) and turned to a diameter of $30 \mathrm{~mm}$. Each specimens has turned to have 3 segments and grooves in between them each segment has $30 \mathrm{~mm}$ in diameter and $15 \mathrm{~mm}$ in length as shown in fig 2. By applying different parameters on each segment, this long specimen can be utilized as three different specimens.

As shown in Figure 2. First, turning operation is completed on one end of the specimen which clamped on the three-jaw chuck during the burnishing operation, while facing and center drilling operations are applied on the other end of the specimen. Then, the specimen is held in between the chuck and tailstock of lathe. A high speed steel single point cutting tool is fixed in the tool post of the lathe and specimen turned to have three steps and grooves in between them. In actual experiments, by applying different parameters on various steps, this specimen can be utilized as three different specimens.

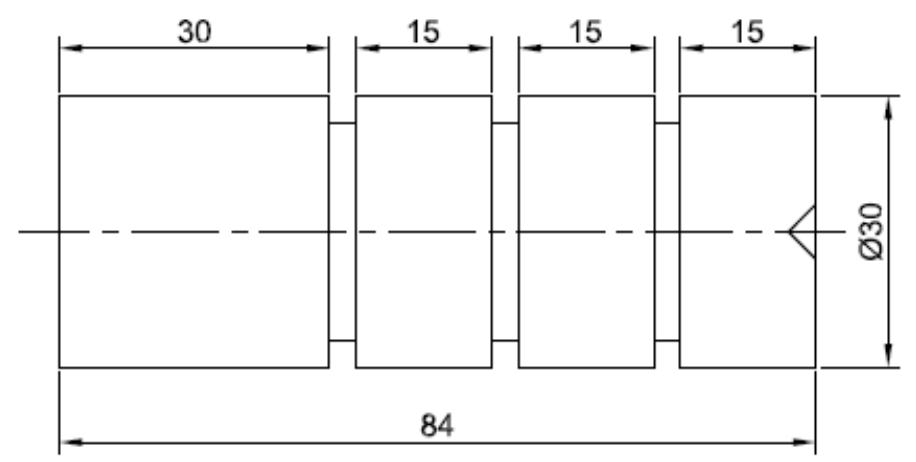

Fig. 2: Dimensions of the AISI 1018 Low Carbon Steel Specimen.

\subsection{Burnishing tool}

The tool employed in the experiments was designed and constructed, as shown in (Fig. 2). It consists of a ball made out of Carbon chromium steel, with a diameter of $8 \mathrm{~mm}$, and having $80 \mathrm{HRC}$ and arithmetic mean average of surface roughness $(\mathrm{Ra})$ 0.01. The ball is in solid contact only with the surface to be burnished, and is guided by 12 idler balls to be free to roll in any direction on the surface of the work piece. One tool was used for single ball burnishing, while two tools were employed for double ball burnishing as shown in fig. 3 . 


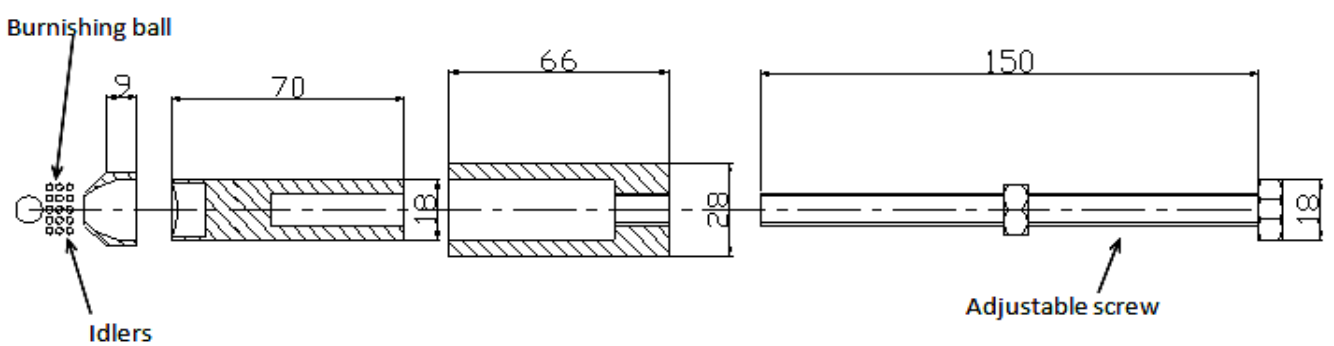

Fig. 3: Burnishing Tool.

Dim. in mms

The shank of one of the burnishing tools is designed in such a manner that it can be simply mounted or fixed onto the tool holder of the lathe machine, while the other tool is mounted on a special holder. This holder is fixed on the lathe saddle to move with it as one part. Then variable feed rates for burnishing were applied for the tools by the lathe saddle. The tools were properly aligned and leveled using laser total station. As shown in figure 4. each burnishing tool is ended with a hexagonal head adjustable screw which was tightened with a torque arm wrench to obtain the required burnishing forces.

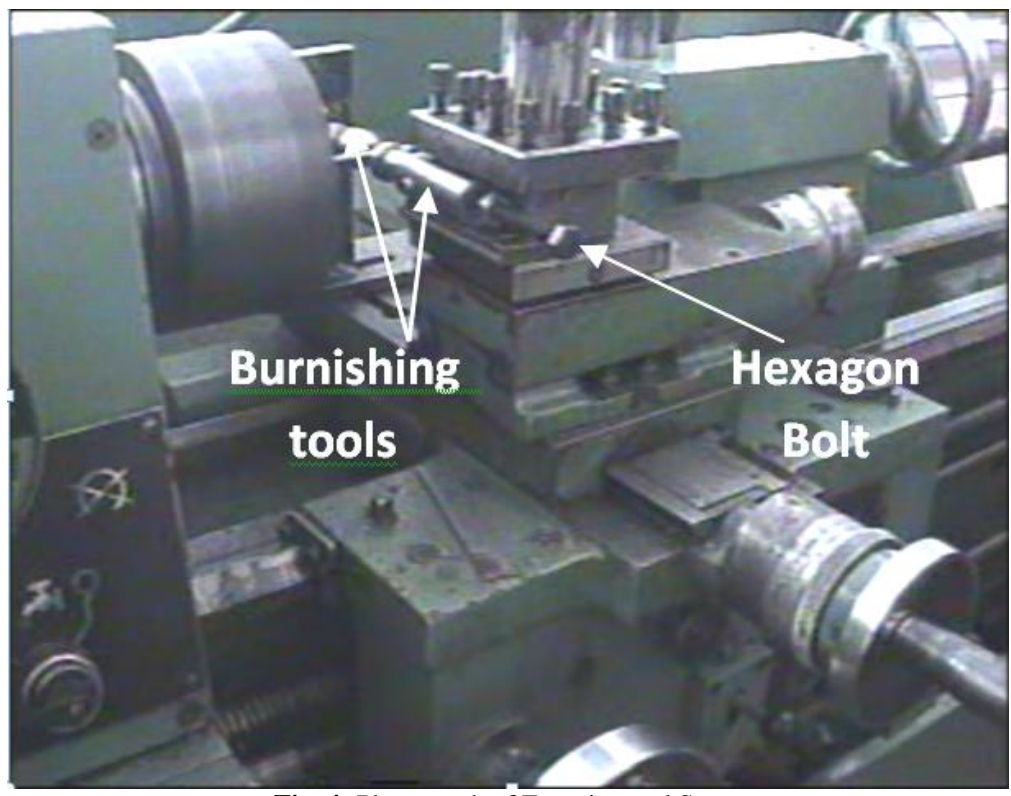

Fig. 4: Photograph of Experimental Setup

\subsection{Experimental procedure}

The burnishing process is conducted on test specimens prepared by turning and alcohol was used to clean the specimens after turning. The cleaning of the ball was carried out continuously in order to prevent any hard particles from entering the contact surface between the tool and specimen.

The specimen to be burnished is clamped by the three-jaw chuck of the lathe and guided from other side by the lathe tailstock. The burnishing process was applied after turning without releasing the specimen from the lathe chuck to keep the same turning alignment.

Initial dry turning conditions were unified for all specimens as follows:

Cutting speed $=57 \mathrm{~m} / \mathrm{min}$., depth of cut $=0.25 \mathrm{~mm}$, feed rate $=0.32 \mathrm{~mm} / \mathrm{rev}$, , and tool nose radius of $0.2 \mathrm{~mm}$.

In this work, produced surface roughness, were measured after turning and burnishing process.

The surface roughness was measured using Taylor Hobson Talysurf model PGI 420. The measurements were carried out across the lay using diamond stylus of radius 2.5 microns and adjusted meter cut-off 0.8 mm. Five readings of surface roughness (measured by Ra) were taken for each specimen, and the average values are calculated. The surface roughness value of turned specimens has been measured and the average value of Ra was $2.4 \mu \mathrm{m}$.

As the aim of this investigation was to study the effect of the new burnishing tool in both single and double ball burnishing process upon final surface roughness and to study the effect of burnishing parameters namely burnishing feed, burnishing speed, and burnishing force upon final surface roughness. The applied Burnishing processes parameters and conditions are listed in table 1. 
Table 1: Burnishing Parameters and Conditions

\begin{tabular}{ll}
\hline Burnishing feed(f) $\mathrm{mm} / \mathrm{rev}$. & $0.09,0.11$, and 0.16 \\
\hline Burnishing speed $\mathrm{m} / \mathrm{min}$. & $10.5,29.6,60.3,85.7$, and 116.5 \\
Burnishing force $(\mathrm{P}) \mathrm{N}$ & 150,210, and 270 \\
Burnishing conditions & Lubricant \\
\hline
\end{tabular}

\section{Results and discussion}

\subsection{Effect of burnishing speed}

The relations between burnishing speed and surface roughness are shown in figure 5. It showed the effect of burnishing speed on surface roughness at constant feed rate of $0.11 \mathrm{~mm} / \mathrm{rev}$., under different burnishing forces $(150 \mathrm{~N}, 210 \mathrm{~N}, 270 \mathrm{~N})$. It can be seen from fig. 5a, considering a single ball burnishing process, the increasing of speed decreases the surface roughness for the force $150 \mathrm{~N}$, but in figure $5 \mathrm{~b}$ and $\mathrm{c}$ for the forces $210 \mathrm{~N}$ and $270 \mathrm{~N}$ surface roughness first decreased with the increase of speed up to a speed of $60.3 \mathrm{~m} / \mathrm{min}$. then slightly increased for further increasing of speed. The rate of increasing with a force of $270 \mathrm{~N}$ is higher than that with the force of $210 \mathrm{~N}$. This may partially, be due to chatter which is usually existed at high speeds with high forces. Figure 5c. Also showed that, at low speeds the surface roughness is optimum at a force of $270 \mathrm{~N}$, while the worst one was obtained in figure 5a with a force of $150 \mathrm{~N}$. This can be attributed to the fact that, at low speeds the deformation action of the ball is high which deteriorates the surface roughness. In this case high force is required to press the peaks of the burnished surface. But at high speeds the reverse was true. Figure $5 \mathrm{~b}$ also showed that, the minimum surface roughness was obtained at a speed of $60.3 \mathrm{~m} / \mathrm{min}$. and burnishing force of $=210 \mathrm{~N}$ at $0.11 \mathrm{~mm} / \mathrm{rev}$. feed.

In situation where double balls were used for burnishing fig. 5, it can be noticed from figure 5a that, using low burnishing force $(150 \mathrm{~N})$ the surface roughness is increased as the speed increased. The same result was obtained when using the force $210 \mathrm{~N}$ but with a lower gradient as it can be seen from figure $5 \mathrm{~b}$. While figure $5 \mathrm{c}$. Showed that the burnished surface roughness is reduced as the speed increase at the burnishing force of $270 \mathrm{~N}$. It can be noticed from figure $5 \mathrm{~b}$ and $\mathrm{c}$ also that, the range of variation of surface roughness for different speeds at the forces 210 , and $270 \mathrm{~N}$ is minimum than that of single ball burnishing. This can be referred to the use of a second ball which prevents the elastic deformation and whirling of the specimen which reduces vibration between the tool and specimen causing minimization for the speed variation's effect on the existence of vibration between tool and specimen. As it can be seen from figure $5 \mathrm{c}$ at low speed also $(10.5 \mathrm{~m} / \mathrm{min}$.) the surface roughness for the force $270 \mathrm{~N}$ is greater than other forces and this may be due to over hardening caused for the specimen surface under the action of this force.

It can be seen also from Fig. 5a, b and c that, the range of surface roughness obtained by double ball burnishing is less than that obtained by single ball burnishing. For double ball burnishing better surface roughness can be achieved using low values of forces with low speeds, or using high forces with high speeds.

(A)

$\mathrm{P}=150 \mathrm{~N}$

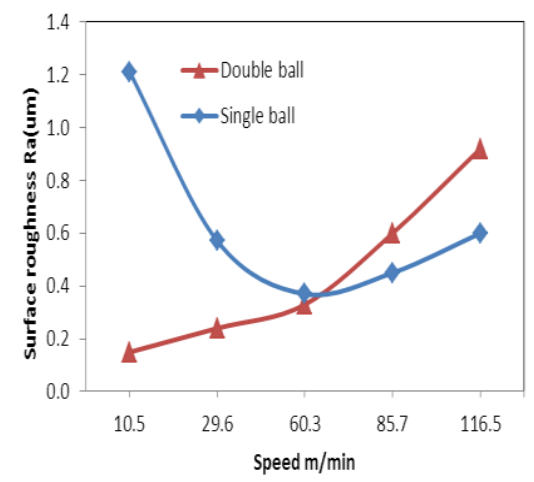

(B)

$P=210 \mathrm{~N}$

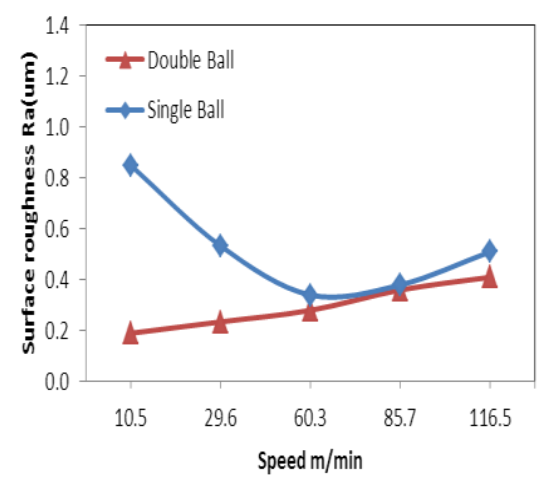

(C)

\section{$P=270 \mathrm{~N}$}

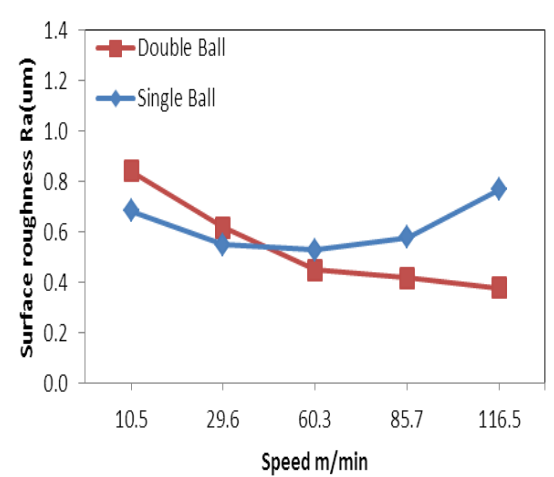

Fig. 5: Effect of Burnishing Speed on Surface Roughness at Loads (A) 150 N, (B) 210 N and (C) $270 \mathrm{~N}$.

\subsection{Effect of burnishing force}

The burnishing force experiments conducted at constant speed of $60.3 \mathrm{~m} / \mathrm{min}$ under different feed rates of $0.09,0.11$ and 0.16. It can be observed from Fig. $6 \mathrm{a}, \mathrm{b}$ and $\mathrm{c}$ that the increase in burnishing force in both single and double ball burnishing process from 90 to $210 \mathrm{~N}$ at feed rates 0.09 , and $0.11 \mathrm{~mm} / \mathrm{rev}$. leads to a decrease in surface roughness. Then further increase of the force above $210 \mathrm{~N}$ leads to an increase of surface roughness at the mentioned feeds. For feed rate of 0.16 the behavior is different as the increase of the force from 90 to $150 \mathrm{~N}$ decreases the surface roughness, while beyond this value of the force the surface roughness increases as the force increase. This may be because high forces cause gradual shear failure in the subsurface layer which, in turn, causes surface flaking. However the highest surface 
smoothness is obtained by double ball burnishing at forces $150 \mathrm{~N}$, and $210 \mathrm{~N}$ at a feed rate of $0.11 \mathrm{~mm} / \mathrm{rev}$. Further increase in the feed with high force deteriorates the surface finish.

(A)

$\mathrm{f}=0.09 \mathrm{~mm} / \mathrm{rev}$

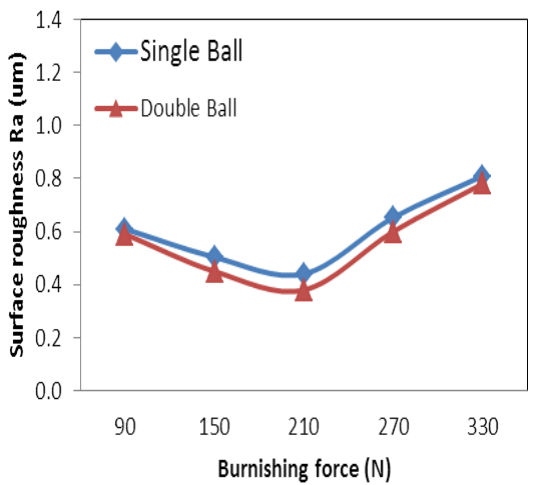

(B)

$\mathrm{f}=0.11 \mathrm{~mm} / \mathrm{rev}$

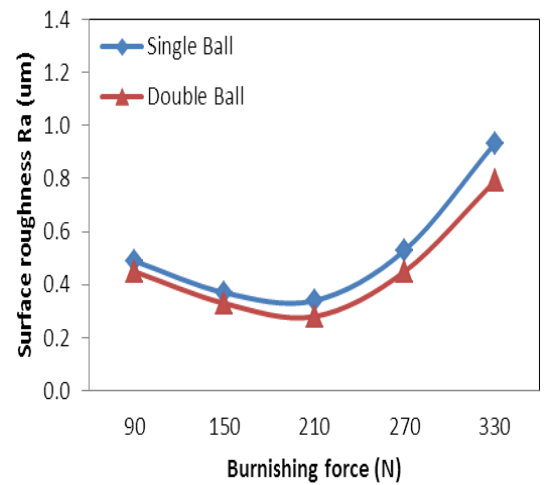

(C)

$\mathrm{f}=0.16 \mathrm{~mm} / \mathrm{rev}$

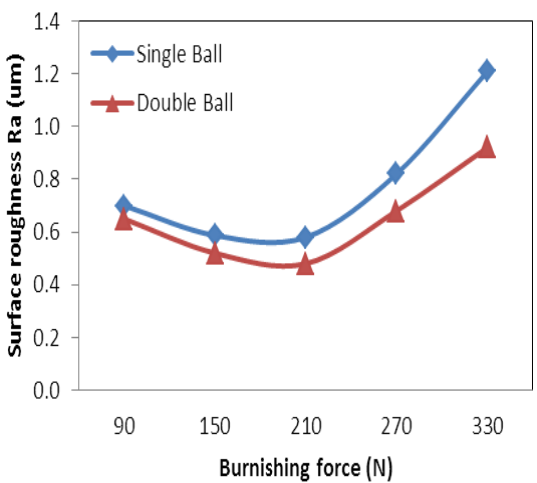

Fig. 6: Effect of Burnishing Force on Surface Roughness at Different Feeds: (A) $0.09 \mathrm{Mm} / \mathrm{Rev}$,(B) $0.11 \mathrm{~mm} / \mathrm{Rev}$ and (C) $0.16 \mathrm{~mm} / \mathrm{Rev}$

\subsection{Effect of number of tool passes}

The effect of number of tool passes on surface roughness has been investigated keeping the burnishing force, feed rate and burnishing speed constant $(\mathrm{V}=60.3 \mathrm{~m} / \mathrm{min}, \mathrm{f}=0.11 \mathrm{~mm} / \mathrm{rev}$ and $\mathrm{F}=210 \mathrm{~N})$. For the double and single ball burnishing process.

To apply a number of burnishing tool passes upon the specimens for both single and double ball burnishing process, first segment of the specimen, the segment close to the lath tailstock, is finished with a single ball burnishing tool one time by keeping the burnishing force, feed rate and burnishing speed constant. After that, the second segment is finished two times, the third segment three times. Then the specimen has been released and the second specimen is held in between the chuck and tailstock of lathe and the finishing process by a single ball burnishing tool is continued up to third segment of the second specimen to finish six passes. The previous steps have been implemented for the double ball burnishing process up to six passes. Corresponding surface roughness values (Ra) are measured on all these segments as shown in figure 7.

Both single and double ball burnishing curves in figure 7 indicated that the surface roughness reached a minimum value by increasing the number of burnishing tool passes, after which it started to increase with further increase in the number of passes. As it can be seen from the curves in figure 7 a reduction in surface roughness is taking place up to the third pass in case of double ball burnishing, while it happened in the single ball burnishing up to the fourth pass. Beyond these number of tool passes on both cases the surface roughness started to increase. In each pass, the tool is being applied under a constant burnishing force to the plastically-deformed surface of the previous pass. Similarly to the effect of burnishing force, after a particular number of passes, the surface layer becomes highly work-hardened, causing flaking to occur. This will lead to the deterioration of the surface and an increase in the surface roughness. Despite of both single and double ball burnishing improved the surface roughness with respect to no of passes, the investigation showed that double ball burnishing process achieved the minimum value of surface roughness with minimum number of tool passes.

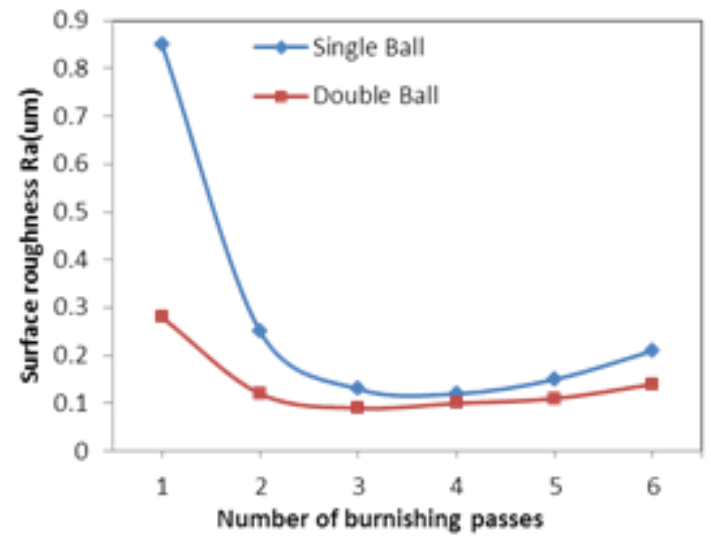

Fig. 7: Variation of Surface Roughness with the Number of Burnishing Tool Pass 


\section{Conclusions}

A new ball burnishing technique was introduced in this investigation which enables both single and double ball burnishing process in site after turning without releasing the specimen. Effect of burnishing parameters upon final surface was demonstrated.

1) Burnishing results showed that, the burnishing tool has a significant improvement of the surfaces resulted from the process. The surface roughness of the turned test specimens were improved by burnishing from about Ra $=2.4$ to about $0.09 \mu \mathrm{m}$,

2) For the investigated material in this work the optimal value for burnishing force which gave minimum surface roughness was $210 \mathrm{~N}$.

3) The surface roughness decreases to a minimum value with the increase in the number of burnishing tool passes, in both single and double ball burnishing processes. After attaining a minimum value, it starts to increase with number of burnishing tool passes.

4) Optimum condition of a Surface finish is obtained with double ball burnishing process at burnishing force of $210 \mathrm{~N}$, speed of $85.7 \mathrm{~m} / \mathrm{min}$, burnishing feed of $0.11 \mathrm{~mm} / \mathrm{rev}$, and number of tool pass was three.

\section{References}

[1] R. Singh, (2011). Process capability study of rapid casting solution for aluminum alloys using three-dimensional printing. International Journal of Automotive and Mechanical Engineering, 4: 398-405. http://dx.doi.org/10.15282/ijame.4.2011.2.0032.

[2] R. Singh, (2012). Comparison of poly jet printing and solution moulding as rapid plastic moulding solution. International Journal of Automotive and Mechanical Engineering, 6, 777-785. http://dx.doi.org/10.15282/ijame.6.2012.9.0063.

[3] N. M. Z. N. Mohamed, \& Khan, M. K. (2012). Decomposition of manufacturing processes: A review. International Journal of Automotive and Mechanical Engineering, 5, 545-560. http://dx.doi.org/10.15282/ijame.5.2012.2.0043.

[4] S. Thamizhmnaii, Bin B Omar, S. Saparudin and S.Hassan. (2008) Surface roughness investigation and hardness by burnishing on titanium alloy. J. Achiev. In Materials \& Manuf. Engg. 28, 139-142.

[5] J.N.Malleswara Rao, A. Chenna Kesava Reddy and P. V Rama Rao., (2011) Experimental investigation of the influence of burnishing tool passes on surface roughness and hardness of brass specimens Indian Journal of Science and Technology Vol. 4 No. 9 ISSN: $0974-6846$.

[6] P. S. Dabeer and G. K. Purohit, (2013).Determination of Surface Roughness by Ball Burnishing Process Using Factorial Techniques, World Academy of Science, Engineering and Technology,Vol:7 -07-27.

[7] X. Yu, L. Wang, (1999)."Effect of various parameters on the surface roughness of an aluminum alloy burnished with a spherical surfaced polycrystalline diamond tool", Int. J. Mach. Tools Manuf. 39, pp (459-469),

[8] A.G. Mamalis, A.I. Grabchenko, M. Horv' ath, I. M'esz' aros, D. Paulmier, (2001)."Ultraprecision metal removal processing of mirrorsurfaces", J. Mater. Process. Technol. 108, pp 269-277.

[9] A.A. Ibrahim et.al., (2009) "Center rest balls burnishing parameters adaptation of steel components using fuzzy logic", Journal of materials processing technology 209, 2428-2435. http://dx.doi.org/10.1016/j.jmatprotec.2008.05.040.

[10] F.J. Shiou, C.C.A. Chen, W.T. Li, (2003)."Automated surface finishing of plastic injection mould steel with spherical grinding and ball burnishing processes". Int. J. Adv. Manuf. Technol. 28, pp 61-66.

[11] L. Luca, Neagu-Ventzel, S., Marinescu, I., (2005)."Effects of working parameters on surface finish in ball-burnishing of hardened steels", Precis. Eng. 29, pp (253-256).

[12] C. H. Chen, and, F. J Shiou. (2003). Determination of optimal ball-burnishing parameters for plastic injection moulding steel. The International Journal of Advanced Manufacturing Technology, 21(3), 177-185. http://dx.doi.org/10.1007/s001700300019.

[13] Fang-Jung Shiou, Chih-Cheng Hsu,(2008)."Surface finishing of hardened and tempered stainless tool steel using sequential ball grinding, ball burnishing and ball polishing processes on a machining centre" journal of materials processing technology 205, pp249-258.

[14] D.B. Patel and T.M. Patel, (2013). "Determination of optimal ball burnishing parameters for surface roughness of aluminum alloy", Journal of Mechanical Engineering and Sciences 4, pp. 472-478, http://dx.doi.org/10.15282/jmes.4.2013.11.0044.

[15] Adel Mahmood Hassan., (1997)."The effects of ball- and roller-burnishing on the surface roughness and hardness of some non-ferrous metals", Journal of Materials Processing Technology 72, 385-391,. http://dx.doi.org/10.1016/S0924-0136(97)00199-4.

[16] S. R. Khalid and M.M. Mayas,(2011)Effect of Roller Burnishing on the Mechanical Behavior and Surface Quality of O1 Alloy Steel, Research Journal of Applied Sciences, Engineering and Technology 3(3), 227-233. 